\title{
O PORTO MARAVILHA e A GeStÃo PÚblica dA PEQUENA ÁFRICA
}

\section{ARTIGO ORIGINAL}

BRANDÃO, Tatiana Lima ${ }^{1}$

PEIXOTO, Felipe dos Santos ${ }^{2}$

BRANDÃO, Tatiana Lima. PEIXOTO, Felipe dos Santos. O Porto Maravilha e a Gestão pública da Pequena África. Revista Científica Multidisciplinar Núcleo do Conhecimento. Ano 05, Ed. 08, Vol. 08, pp. 72-91. Agosto de 2020. ISSN: 2448-0959, Link de acesso: https://www.nucleodoconhecimento.com.br/administracao/portomaravilha

\section{RESUMO}

Este artigo aborda a importância da região denominada Pequena África para a história da cidade do Rio de Janeiro e para a formação da população brasileira a partir do Projeto Porto Maravilha. Com a criação da sociedade de economia mista Companhia de Desenvolvimento Urbano da Região do Porto do Rio de Janeiro (CDURP), gestora da prefeitura na Operação Urbana Consorciada Porto Maravilha, a revitalização da região portuária pôde ser concretizada e a história da Pequena África resgatada.

${ }_{1}$ Pós Graduada em Contabilidade Pública pela Faveni e em Geologia do Quaternário com ênfase em Arqueologia pela Universidade Federal do Rio de Janeiro (UFRJ), Graduada na Universidade Federal do Estado do Rio de Janeiro (UNIRIO) em História e em Administração Pública, também em Gestão de Turismo pelo CEFET - RJ.

2 Orientador. MBA em Gestão de Projetos. FGV, conclusão em 2020. Extensão em Smart Cities. UFF, conclusão em 2019. Graduado em Direito. UNILASALLE, conclusão em 2010. Pós-graduado em Direito Público. ESA/OAB-RJ, conclusão em 2006. Graduado em Administração. UFF, conclusão em 2004. 
Através da análise bibliográfica e da documentação do Projeto Porto Maravilha verificar-se-á como foi feita a gestão pública da região em questão.

Palavras-chave: Gestão Pública, pequena África, Porto Maravilha.

\section{INTRODUÇÃO}

Atualmente denominada como Pequena África, parte da região portuária da cidade do Rio de Janeiro ganhou uma importância histórica e turística a partir das obras de revitalização do projeto Porto Maravilha. Com a (re)descoberta do Cais do Valongo, em 2011, a memória da escravidão trouxe à tona um local símbolo da diáspora africana do século XIX, recebendo o título de Patrimônio da Humanidade pela Organização das Nações Unidas para a Educação, a Ciência e a Cultura (UNESCO) em julho de 2017.

Segundo a Companhia de Desenvolvimento Urbano da Região do Porto do Rio de Janeiro (CDURP), gestora da prefeitura na Operação Urbana Consorciada Porto Maravilha, devido à tamanha importância não somente para a história do Rio de Janeiro como também para a compreensão do processo de escravidão e da formação da sociedade brasileira, foi criado o Circuito Histórico e Arqueológico da Herança Africana, pelo Decreto № 34.803 de 29 de novembro de 2011 (CDURP, 2012).

Assim, como a gestão pública do projeto Porto Maravilha, com o objetivo a requalificação e reurbanização da Região Portuária da cidade, proporcionou a valorização histórico turística da região denominada Pequena África a partir da redescoberta do Cais do Valongo?

A partir desta questão, parte-se em busca das seguintes suposições: a criação da Companhia de Desenvolvimento Urbano da Região do Porto do Rio de Janeiro, gestora do Porto Maravilha, contribuiu para a valorização histórico turística da região Pequena África; o Programa Porto Maravilha Cultural ajudou a fomentar o Circuito de Herança Africana e a divulgá-lo; houve de fato um fomento na região e uma preocupação com a preservação do patrimônio e sua valorização. 
Este artigo tem como objetivo a análise da gestão pública e patrimonial de valorização histórico turística da região denominada Pequena África realizada pela CDURP. Além disso, busca fazer uma breve revisão da bibliografia historiográfica sobre os pontos turísticos da Pequena África pertencentes ao Circuito Histórico e Arqueológico da Celebração da Herança Africana; diagnosticar as ações que culminaram na criação do Circuito e na sua consequente manutenção; e discutir o papel da gestora CDURP na Operação Urbana Consorciada Porto Maravilha, em relação ao patrimônio histórico da região.

A metodologia utilizada foi uma revisão bibliográfica com abordagem qualitativa por meio de um levantamento teórico e historiográfico através da revisão de alguns livros, artigos e dissertações. Após essa análise, foi feito o levantamento da documentação do projeto Porto Maravilha relacionado à parte de preservação e restauração da área em questão e, a partir desses dados, chegou-se à discussão sobre o papel da CDURP na gestão, recuperação e preservação da área.

Este estudo justifica-se pela análise da valorização histórico turística da região Pequena África que, antes das obras do Porto Maravilha, estava entregue à degradação e à violência e, principalmente, à margem do esquecimento. A região em questão recebe esse nome em virtude da importância do Cais do Valongo, porto de entrada de milhares de escravizados africanos no país e que, com a abertura do sítio arqueológico, pôde se candidatar e receber o título de Patrimônio Histórico da Humanidade em 2017.

A história da Pequena África necessita de políticas públicas de incentivo a sua preservação atrelada ao fomento turístico da região. O incentivo ao turismo cultural e patrimonial é uma maneira de ampliar a percepção do passado e de vivenciar as raízes do povo brasileiro. Faz-se necessária a preservação desse patrimônio históricocultural a fim de fortalecer a identidade cultural e a herança das raízes africanas que fazem parte da formação da cultura brasileira como um todo e da própria população do país. 


\section{FUNDAMENTOS TEÓRICOS}

A partir do processo de democratização no Brasil instituído com a Constituição Federal de 1988, a política de desenvolvimento urbano pôde ser melhor definida, materializando-se, de acordo com Libório (2016, p.06), "na forma de um programa de ação governamental voltado à ordenação dos espaços habitáveis, abrangendo, dessa forma, tanto o planejamento quanto a gestão das cidades".

Os artigos 182 e 183 da Constituição Brasileira apresentam como objetivo do Poder Público municipal ordenar o pleno desenvolvimento das funções sociais da cidade e garantir o bem-estar de seus habitantes (BRASIL, 2019). Em outras palavras, o texto constitucional apresenta a política de desenvolvimento urbano local como competência dos municípios.

Para concretizar tais objetivos, a lei federal $\mathrm{n}^{\circ}$ 10.257, de 10 de julho de 2001, mais conhecida como Estatuto da Cidade, regulamentou tais artigos da Carta Magna e estabeleceu os principais instrumentos da política urbana, dentre eles a operação consorciada urbana (artigo $4^{\circ}$ ), além das diretrizes gerais (artigo $2^{\circ}$ ), tais como:

III - cooperação entre os governos, a iniciativa privada e os demais setores da sociedade no processo de urbanização, em atendimento ao interesse social;

IV - planejamento do desenvolvimento das cidades, da distribuição espacial da população e das atividades econômicas do Município e do território sob sua área de influência, de modo a evitar e corrigir as distorções do crescimento urbano e seus efeitos negativos sobre o meio ambiente;

$\mathrm{V}$ - oferta de equipamentos urbanos e comunitários, transporte e serviços públicos adequados aos interesses e necessidades da população e às características locais; (...)

XII - proteção, preservação e recuperação do meio ambiente natural e construído, do patrimônio cultural, histórico, artístico, paisagístico e arqueológico (BRASIL, 2001, p.02).

Com o intuito de concretizar as funções sociais da cidade, sejam elas a infraestrutura, transporte, moradia, serviços públicos, lazer, dentre outros, a Prefeitura da Cidade do 
Rio de Janeiro criou a empresa pública Companhia de Desenvolvimento Urbano da Região do Porto do Rio de Janeiro (Cdurp) para gerenciar a Operação Urbana Consorciada (OUC), um dos instrumentos do Estatuto das Cidades. De acordo com a Lei ํㅜ 10.257/2001, que estabelece diretrizes gerais da política urbana,

Considera-se operação urbana consorciada o conjunto de intervenções e medidas coordenadas pelo Poder Público municipal, com a participação dos proprietários, moradores, usuários permanentes e investidores privados, com o objetivo de alcançar em uma área transformações urbanísticas estruturais, melhorias sociais e a valorização ambiental (BRASIL, 2001, p.03).

Assim, de acordo com a própria Cdurp (2020), o Porto Maravilha é uma OUC "criada em 2011 para revitalizar e desenvolver a Região Portuária do Rio de Janeiro até 2026 por meio de uma parceria público privada de 15 anos renováveis pelo mesmo período".

As intervenções possibilitaram a requalificação e reurbanização da Região Portuária da cidade do Rio de Janeiro, uma região outrora degradada. "O Porto Maravilha foi desenvolvido para a recuperação da infraestrutura urbana, dos transportes, do meio ambiente e dos patrimônios histórico e cultural da Região Portuária" (CDURP, 2020). Diversas obras foram realizadas, dentre elas a demolição do elevado da Perimetral, substituindo-o pelas construções do Túnel Rio 450, da via Binário do Porto, da Via Expressa e do Túnel Prefeito Marcello Alencar; a construção do Museu de Arte do Rio (MAR) e o Museu do Amanhã, localizados na Praça Mauá; a implementação sustentável do Veículo Leve sobre Trilhos (VLT), integrando diversos modais de transporte da região, como o terminal de cruzeiros Píer Mauá, a rodoviária, o aeroporto Santos Dumont, o metrô, o teleférico da Providência e os ônibus como um todo.

Além de inúmeras obras de infraestrutura urbana de água, esgoto, drenagem, iluminação pública, ciclovias e plantios de árvores, o Porto Maravilha também possui compromissos sociais com a geração de empregos, habitações de interesse social, formalização das atividades econômicas, formação profissional e a valorização do Patrimônio Material e Imaterial da região. Com esse intuito, foram criados diversos programas e projetos para fomentar a região portuária. 
A Cdurp, responsável pela requalificação da Região Portuária, criou os programas Porto Maravilha Cidadão e Porto Maravilha Cultural para articular ações e parcerias nesse sentido. A legislação determina que $3 \%$ da arrecadação dos Cepacs sejam aplicados em projetos de recuperação e valorização dos patrimônios histórico e cultural (CDURP, 2011, p. 01).

Ao criar o programa Porto Maravilha Cultural, a Cdurp tem o intuito de aplicar os recursos na restauração de bens tombados, em ações do poder público e no apoio a iniciativas de valorização do patrimônio da região.

Considerada uma região à margem da sociedade tanto do ponto de vista econômico, como social e organizacional, Costa (2015) mostra como a região transformou-se completamente, saindo do estado de degradação e abandono que se encontrava até o início da implantação do Porto Maravilha.

Tendo em vista a Operação Urbana Consorciada da Área de Especial Interesse Urbanístico da Região Portuária do Rio de Janeiro, que consta na Lei Municipal 101/2009, o estudo da gestão e da história de alguns locais da Pequena África são importantes para a valorização histórico-turística da região portuária.

\subsection{PROJETO PORTO MARAVILHA}

A cidade do Rio de Janeiro foi preparada para os megaeventos como a Copa do Mundo de Futebol de 2014 e, principalmente, as Olimpíadas de 2016. Com isso, a cidade passou por inúmeros projetos de reestruturação, dentre eles, o projeto Porto Maravilha. A versão oficial explicitava a preocupação em enquadrar o Rio de Janeiro nos novos moldes das chamadas cidades globais.

Sancionada em dezembro de 2009 pelo prefeito Eduardo Paes, o projeto municipal que instituiu a Operação Urbana Consorciada (OUC) pela Lei Complementar 101/2009 mudou os ares não só da Região Portuária do Rio de Janeiro, mas de um total de 5 milhões de metros quadrados $\left(\mathrm{m}^{2}\right)$, uma Área de Especial Interesse Urbanístico (AEIU) da Região do Porto que estava entregue ao abandono e à degradação. 
Mapa 01 - Área de especial interesse urbanístico: bairros principais: Santo Cristo, Gamboa, Saúde e Centro

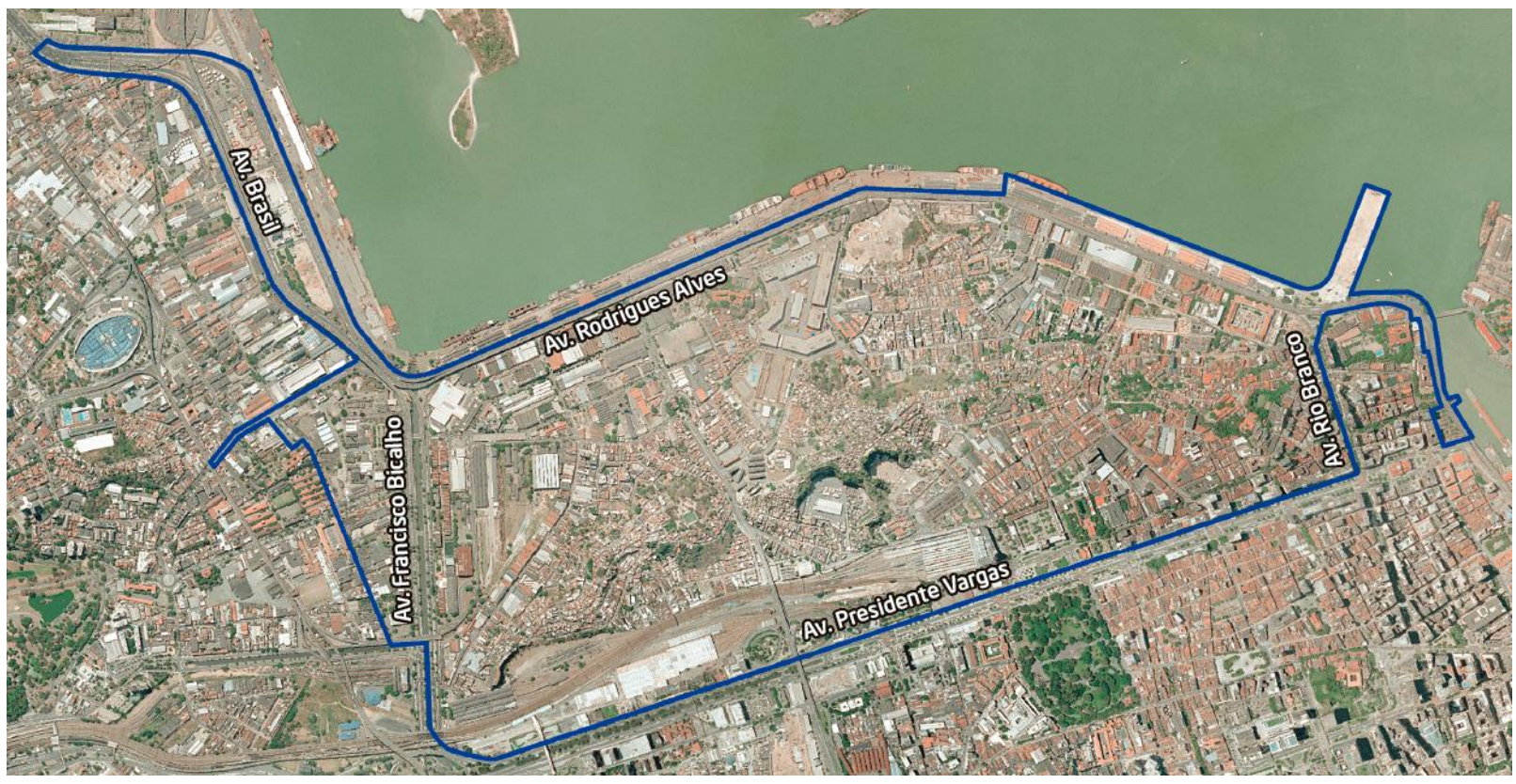

Com o objetivo de alcançar transformações urbanísticas, melhorias sociais e valorização ambiental, a OUC visou alcançar uma reestruturação em toda a área, por meio da ampliação, articulação e requalificação dos espaços livres de uso público.

A referida Lei Complementar 101/2009 instituiu que a aplicação de pelo menos 3\% dos recursos arrecadados com Certificados de Potencial Adicional de Construção (Cepacs) fossem investidos na recuperação e valorização desse patrimônio e no fomento à atividade cultural (RIO DE JANEIRO, 2009).

Com a implantação do Programa Porto Maravilha Cultural, tais recursos são aplicados em linhas de ação como a preservação e valorização da memória, do patrimônio e das manifestações culturais, além da recuperação e restauro material de tal patrimônio e a sua exploração econômica (RIO DE JANEIRO, 2009, p.10). E com a redescoberta do Cais do Valongo e da Imperatriz, em fevereiro de 2011, durante as escavações para as obras da nova rede de drenagem na Avenida Barão de Tefé, a importância histórica da região aumentou. 
Assim, em 2011, entrou em vigor o Decreto 34.803, criando oficialmente o Circuito Histórico e Arqueológico de Celebração da Herança Africana em virtude de inúmeras considerações como a importância histórica e cultural da região, a necessidade de mostrar à população os achados arqueológicos do Cais do Valongo e do Cemitério dos Pretos Novos a fim de preservar sua história e memória dos milhares de escravos que passaram pela região da Pequena África.

Art. 1ํ Fica criado o Circuito Histórico e Arqueológico de Celebração da Herança Africana, (...) que inclui os seguintes espaços vinculados à história e à cultura afro-brasileira:

I - Centro Cultural José Bonifácio;

II - Cemitério dos Pretos Novos (Instituto Pretos Novos);

III - Cais do Valongo e da Imperatriz;

IV - Jardins do Valongo;

V - Largo do Depósito; e

VI - Pedra do Sal (RIO DE JANEIRO, 2011, p.01)

Mapa 02 - Circuito Histórico e Arqueológico de Celebração da Herança Africana

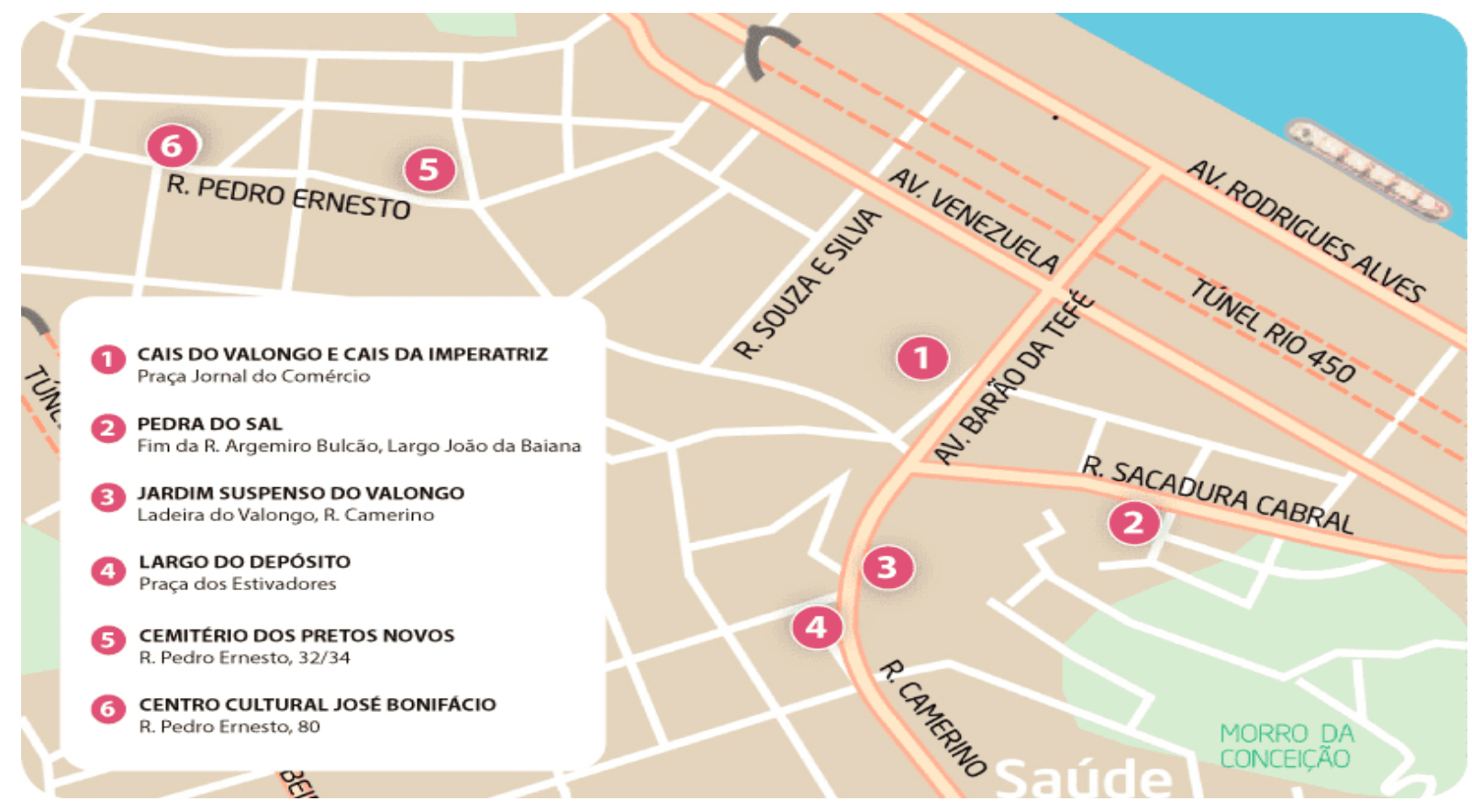


De acordo com os relatórios do Porto Maravilha e com a pesquisa feita por Costa (2015), diversas medidas foram realizadas em prol da valorização histórico-cultural da região, tais como visitas guiadas pelo Circuito Histórico; abertura do espaço de exposições "Meu Porto Maravilha", próximo ao Cais do Valongo; obras de restauro dos Galpões da Gamboa e do Centro Cultural José Bonifácio; a instalação de sinalização em português e inglês nos seis pontos do Circuito; oficialização do Cais do Valongo como Patrimônio Cultural da Cidade do Rio de Janeiro e placa de identificação e valorização da área do Quilombo da Pedra do Sal, também como Patrimônio da cidade; dentre inúmeros outros.

\subsection{A HISTÓRIA DA PEQUENA ÁFRICA E O CIRCUITO DE HERANÇA AFRICANA DO PROGRAMA PORTO MARAVILHA CULTURAL}

Compreender a história dos locais que compõe a Pequena África é de suma importância não somente para a História do Rio de Janeiro, a do Brasil ou até mesmo a mundial, mas também traz reflexões acerca de toda uma cultura secular envolvida para além da memória da escravidão e como essa representatividade é vista hoje, depois de tanto tempo silenciada.

Segundo Gomes (2014), a região da cidade do Rio de Janeiro denominada Pequena África foi assim caracterizada pelo artista e sambista Heitor dos Prazeres, no início do século $\mathrm{XX}$, como um local de herança da diáspora africana e sua resistência através da cultura, da religiosidade e da musicalidade ao longo dos anos.

Heitor dos Prazeres foi um dos precursores da arte multimídia, tendo criado o figurino e a cenografia para o Ballet do Quarto Centenário da Cidade de São Paulo. Compôs cerca de 300 músicas entre sambas canções, baiões, marchas, frevos, boleros, fox, mambos e outros ritmos. $\mathrm{Na}$ década de 30, como músico, atuou com seu conjunto de ritmistas, passistas e cabrochas no lendário Cassino da Urca no Rio de Janeiro ao lado de astros e estrelas como Grande Otelo e Josephine Baker, é desta época a sua participação no filme "It's All True" de Orson Welles" (KRISNAS, 2009, p.09).

Após a abolição da escravidão, em 13 de maio de 1888, na região que se estendia desde o cais do porto até a Cidade Nova viveram escravizados alforriados, seus 
descendentes e muitos advindos especialmente da Bahia e de antigas áreas cafeeiras do Vale do Paraíba em busca de trabalho no Rio de Janeiro em seu principal porto de exportação.

Com o tempo, de acordo com Rodrigues (2013), a expressão Pequena África passou a identificar parte da zona portuária do Rio de Janeiro marcando a presença africana e o patrimônio cultural na história brasileira em busca da manutenção de suas memórias.

Entre o final do século XVIII e a primeira metade do século XIX, a região foi marcada pelo comércio dos africanos escravizados, caracterizando a área com uma dor e um sofrimento que não podem ser esquecidos. No século XVIII, a região do Valongo (vale longo) era de difícil acesso por estar isolada entre os morros da Conceição, do Livramento, da Saúde e do Pinto, transformando-se em local ideal para retirar do coração da cidade, na Rua Direita, atual Primeiro de Março, todo o comércio de escravos, contribuindo para a dinamização da área.

Com a vinda da Família Real juntamente com a Corte Portuguesa, em 1808, a cidade do Rio de Janeiro passou por grandes transformações. Com base nisso e de acordo com Honorato (2008), a Intendência Geral de Polícia da Corte da Cidade do Rio de Janeiro foi criada, no mesmo ano, com o intuito de assegurar o controle da segurança pública a fim de tornar a cidade mais civilizada na visão da época, melhorando seu aspecto através de obras públicas e de abastecimento.

Segundo Soares (2013), a Coroa Portuguesa não somente mandou edificar esse novo cais como também um Lazareto, em 1810, espécie de hospital para escravos novos ficarem isolados até estarem completamente curados. A construção do Cais do Valongo demorou seis anos para se concretizar, tendo uma extensão de 24 por 22 metros, tornando-se a porta de entrada de quase um milhão de escravos africanos, em sua maioria, vindos do Congo e de Angola.

Pouco tempo depois, em 7 de novembro de 1831, foi promulgada a Lei Feijó, a primeira lei de proibição do tráfico Atlântico de escravos para o Brasil, ocasionando a 
desativação oficial do cais. Sendo remodelado para apagar essa memória escravocrata com a chegada de Tereza Cristina de Borboum, o Cais do Valongo, na tentativa de esconder o local de comércio de escravos, passou-se a chamar Cais da Imperatriz.

A chegada à cidade da princesa dona Teresa Cristina, esposa de Pedro II, em 1843, fez com que o desembarcadouro ali ficasse conhecido como Cais da Imperatriz. Com as futuras reformas, o mar recuaria e essas áreas seriam engolidas pelos aterros. A rua do Valongo se tornaria a rua da Imperatriz e, mais tarde, rua Camerino, enquanto a praia do Valonguinho daria origem a à rua da Saúde, mais tarde rua Sacadura Cabral. A partir de 1870, o nome Valongo começa a cair em desuso e a área passa ser conhecida progressivamente como Saúde (CAVALCANTI, 1998, p. 33).

Dentro do contexto do comércio de escravos na área do Valongo dos séculos XVIII e XIX, que incluía o Lazareto e os depósitos e armazéns de escravos que se concentravam no Largo do Depósito (hoje Praça dos Estivadores), houve o funcionamento do Cemitério dos Pretos Novos. Considerado o maior cemitério de escravos das Américas até hoje encontrado, o Cemitério, do qual se havia perdido a localização, foi descoberto durante as obras de fundação da residência do casal Petrúcio e Mercedes Guimarães, em janeiro de 1996, quando ossos humanos foram encontrados. A partir disso, segundo Pereira (2014), o Departamento Geral de Patrimônio Cultural da Prefeitura da Cidade do Rio de Janeiro foi acionado, bem como o Instituto de Patrimônio Histórico e um grupo de arqueólogos para estudar o local.

O Cemitério dos Pretos Novos funcionou de 1772 a 1830, na região do Valongo, dentro da área limitada pelas ruas Pedro Ernesto, rua Leôncio de Albuquerque e rua do Propósito. Foi transferido da Avenida Marechal Floriano, em frente à Igreja de Santa Rita, que cuidava dos sepultamentos dos escravos desde 1722, para esse novo local justamente por ser uma região mais afastada do coração da elite portuguesa e brasileira.

O Valongo entrou, então, para a história da cidade como um local de horrores. Nele, os escravos que sobreviviam à viagem transatlântica recebiam o passaporte para a senzala. Os que não sobreviviam tinham 
seus corpos submetidos a enterro degradante. Para todos, era o cenário tétrico do comércio de carne humana (PEREIRA, 2014, p.29).

Segundo Honorato (2008), Pretos Novos é a maneira como a sociedade escravista desse período chamava os negros recém-escravizados que entravam no porto do Rio de Janeiro oriundos do continente africano, uma cidade que se tornou importante importador de mão de obra africana e distribuidor do Brasil.

Os que ficavam doentes e morriam eram encaminhados ao Cemitério dos Pretos Novos onde seriam jogados à flor da terra sem nenhum ritual religioso, chegando-se à estimativa de corpos de 20 a 30 mil negros, de acordo com o IPHAN (2016).

A propriedade do casal transformou-se, em 13 de maio de 2005, no Instituto Pretos Novos a fim de valorizar a memória daqueles que ali foram enterrados através de ações de preservação, pesquisa histórica e arqueológica, cursos e visitas guiadas pela região.

Um outro local de grande importância na Pequena África é a Pedra do Sal, localizada entre o Largo João da Baiana e a rua São Francisco da Prainha. Esculpidas por escravos na década de 1830, suas escadas marcam um corte feito na pedra que se projetava sobre o mar e dificultava a passagem à região do Valongo. Para Soares (2013), recebe esse nome em virtude da construção do trapiche Pedra do Sal, em 1840, pertencente ao comerciante Manuel Fernandes da Silva, no local anteriormente chamado Pedra da Prainha ponto de embarque e desembarque de produtos alimentícios, dentre eles o sal. Mas para Rodrigues (2013), recebe tal nome pela salinidade da água da Baía de Guanabara que, quando a maré baixava, deixava a pedra cheia de sal.

Símbolo de resistência desse passado escravizado, após a abolição da escravidão muitos alforriados e seus descendentes ali passaram a morar uma vez que seu entorno oferecia oportunidades de trabalho na região, como nas casas comerciais de café, trapiches e estaleiros. O local tornou-se um espaço cultural negro de herança das festas e da religião, tendo recebido os primeiros terreiros da cidade. 
Já em 1906, durante o período do governo do prefeito Pereira Passos, o projeto denominado "Embelezamento e Saneamento da Cidade" e mais conhecido como o "Bota Abaixo" repercutiu e alterou profundamente a história urbana e arquitetônica do centro e de outras regiões da cidade ao transformar a capital em uma inspiração da Belle Époque Parisiense. Dentro desse contexto, foi construído o Jardim Suspenso do Valongo, próximo aos antigos Cais do Valongo e da Imperatriz, com o intuito de apagar essa memória escravocrata da região, na qual a capital do país não se enquadrava mais. No mesmo local, também foi construído a Casa da Guarda e o Mictório Público.

Segundo KOK (2005), com a determinação da construção de um novo porto para a cidade (atual Píer Mauá), as famosas casas de zungu passaram a ser chamadas de Casas das Tias Baianas ou Casas do Santo e muitos negros foram expulsos do local já em conflito com a Venerável Ordem Terceira da Penitência (VOT), que reclamava o pertencimento das terras. Correa (2016) mostra que com o remodelamento, saneamento e embelezamento da região, a Prefeitura doou o território pleiteado, mas as disputas pela memória afrodescendente continuaram avançando até os dias atuais.

A Pedra do Sal também é marcada pela cultura tradicional do samba carioca uma vez que com a abertura da Avenida Presidente Vargas mudaram-se para a região sambistas de renome como Pixinguinha, João da Baiana e Donga, perpetuando ali uma efervescência musical ligada as tradições da música popular negra.

E essa resistência pela memória da cultura afrodescendente perdura nos dias atuais e, com as reformas do Porto Maravilha o passado pode ser rememorado e sua preservação incentivada.

Além do Cais do Valongo, da Pedra do Sal, do Cemitério Pretos Novos, do Jardim Suspenso do Valongo e do Largo do Depósito conforme vistos, também faz parte do Circuito de Herança Africana o Centro Cultural José Bonifácio, que foi considerado o primeiro colégio público da América Latina, pensado e inaugurado por $\mathrm{D}$. Pedro II em 1877. Atualmente, ele funciona como um centro de referência da cultura afrobrasileira. 


\section{GESTÃO PÚBLICA DA PEQUENA ÁFRICA}

Diante da diversidade de funções que compõem os objetivos do Estado, a Administração Pública não pode ser vista apenas sobre um único prisma. Segundo Carvalho Filho (2018), há um consenso entre diversos estudiosos que a Administração Pública apresenta mais de um sentido.

A partir do sentido objetivo, ela consiste "na própria atividade administrativa exercida pelo Estado por seus órgãos e agentes, caracterizando, enfim, a função administrativa" (CARVALHO FILHO, 2018, p. 09), ou seja, a prestação dos serviços públicos em si a fim de alcançar os interesses da sociedade, o maior objetivo do Estado. Já pelo sentido subjetivo, caracteriza-se pelo "conjunto de agentes, órgãos e pessoas jurídicas que tenham a incumbência de executar as atividades administrativas" (CARVALHO FILHO, 2018, p. 09)), em outras palavras, são os sujeitos da função administrativa, quem a exerce de fato. Sendo assim, integram a Administração Pública não somente os entes da Administração Direta (União, Estado, Distrito Federal e Municípios), como também os da Administração Indireta.

Nesse sentido, a Administração Pública está inserida em uma sociedade complexa sócio, política e economicamente, com múltiplos interesses envolvidos, devendo assim pautar-se nas melhores soluções que possam abranger o maior número de interessados da sociedade, de maneira justa.

De acordo com Cademartori (2010, p. 271), a Administração Pública contemporânea "abandona o seu papel de mero executor e representante de órgãos políticos centralizados, tornando-se mais autônoma na medida em que passa a interagir através de acordos e atos unilaterais com os diversos grupos sociais", na tentativa de adequar-se ao contexto das relações sociais.

Dentro desse contexto, a Cdurp, com a finalidade de promover a reestruturação da região portuária da cidade do Rio de Janeiro e a requalificação de seus espaços, trouxe à tona a execução da valorização histórico turística da região Pequena África por meio de inúmeros feitos, tais como: a restauração do Cais do Valongo e da 
Imperatriz e dos atuais atrativos do Circuito de Herança Africana; a criação de tal Circuito para fomentar o conhecimento da cultura e da História de um povo e de um país; restauro dos Galpões da Gamboa, da Igreja de São Francisco da Prainha; obras de dois grandes museus na região da Praça Mauá - Museu de Arte do Rio e Gestão do Museu do Amanhã; prêmios culturais de fomento à cultura com shows, teatro, cursos, oficinas.

Assim, o Porto Maravilha Cultural ajudou a fomentar o Circuito Histórico e Arqueológico da Celebração da Herança Africana e a fazer a divulgação em seu site e por seu mailing list das visitas guiadas gratuitamente e realizadas pelo Instituto Pretos Novos, além de divulgar também o trabalho de guias de turismo autônomos que realizam a visita guiadas aos lugares da Pequena África.

Os prêmios culturais também ajudaram bastante a valorizar e a preservar o patrimônio da região, tais como a produção de livro e de documentários, aulas gratuitas de educação patrimonial, cinema em movimento nas escolas, artes no Galpão Gamboa, apresentações teatrais a céu aberto, dentre outros.

De fato, houve um fomento na região e uma preocupação com a preservação do patrimônio e sua valorização, mas por conta da obrigação legislativa. $O$ aporte financeiro injetado pela Cdurp foi uma obrigação instituída por lei. Não se pode afirmar que, se não fosse obrigatório, a região teria passado por essa transformação histórica de valorização patrimonial.

\section{CONSIDERAÇÕES FINAIS}

Por meio das inúmeras iniciativas do projeto Porto Maravilha, os impactos foram não somente os de recuperação da região portuária, mas também a sua revitalização que a transformou em um novo local turístico para a cidade do Rio de Janeiro. A Pequena África, cuja delimitação se insere no espaço de revitalização do Porto Maravilha e cujo reconhecimento foi pensado pelo projeto através da restauração e revitalização dos locais explicitados no artigo, é de suma importância para a História do Brasil. Faz-se necessária a preservação desse patrimônio histórico-cultural a fim de fortalecer a 
identidade cultural e a herança das raízes africanas que fazem parte da formação da cultura brasileira como um todo e da própria população do país.

Mas isso tudo só foi possível em virtude da constituição da Cdurp que tinha uma finalidade muito maior do que essa valorização da região. A Gestão Pública Municipal realizada por ela vai além dessa questão. Não se pode esquecer em que momento se vivia para que ela fosse instituída: vésperas de uma Copa do Mundo e de uma Olimpíadas. A cidade do Rio de Janeiro necessitava dessa remodelação na região e, em virtude do Estatuto das Cidades, a preservação e o restauro faziam parte da reestruturação urbanística por lei.

De qualquer forma, a Cdurp alcançou o objetivo, como uma gestora pública e peça fundamental de execução de políticas públicas, de proporcionar a preservação dessa parte da História e, através de inúmeros incentivos, buscou fomentar a região através de um de seus vieses do projeto Porto Maravilha: o Porto Maravilha Cultural.

\section{REFERÊNCIAS}

BRASIL. Constituição (1988). Constituição da República Federativa do Brasil. Brasília, DF: Senado Federal: Centro Gráfico, 2019.

Ministério do Turismo. Turismo Cultural: Orientações Básicas. $3^{\underline{a}}$ ed Brasília, 2010. Disponível em: https://pt.scribd.com/document/356009618/TurismoCultural-Versxo-Final-IMPRESSxO Acesso em: 05/04/2020.

Lei no 10.257, de 10 de julho de 2001. Regulamenta os arts. 182 e 183 da Constituição Federal, estabelece diretrizes gerais da política urbana e dá outras providências. Disponível em http://www.planalto.gov.br/ccivil_03/leis/leis_2001/110257.htm Acesso em: 01/05/ 2020.

CADEMARTORI, Luiz Henrique Urquhart. Reforma da administração pública e globalização: a interligação entre os eventos. Revista da Faculdade de Direito UFMG, Belo Horizonte, n. 56, p. 265-280, jan./jun. 2010. Disponível em: 
https://www.direito.ufmg.br/revista/index.php/revista/article/download/120/112. Acesso em: 21/04/2020.

CARVALHO FILHO, José dos Santos. Manual de Direito Administrativo - 32. ed. rev., atual. e ampl. - São Paulo: Atlas, 2018.

CAVALCANTI, Nireu Oliveira. Rio de Janeiro - Centro Histórico, 1808-1998, Marcos da colônia. Dresdner Bank Brasil, 1998, p.88. In: SOARES, Carlos Eugênio Líbano. Valongo, cais dos escravos: memória da diáspora e modernização portuária na cidade do Rio de Janeiro, 1668 - 1911. Relatório de estágio de pós-doutoramento, Departamento de Antropologia, Museu Nacional (UFRJ), Rio de Janeiro, 2013.

CDURP, Porto Maravilha. Prefeitura cria Circuito Histórico e Arqueológico da Celebração da Herança Africana. Rio de Janeiro, 2011. Disponível em http://www.portomaravilha.com.br/uploads/releases/55cbb33fb9a89.pdf Acesso em: 16/12/2019.

. Apresentação Geral - Porto Maravilha. Rio de Janeiro, 2020. Disponível em

http://www.portomaravilha.com.br/conteudo/portomaravilha/2020portomaravilha.pdf? _t=1585679460 Acesso em: 26/07/2020.

CORREA, Maíra Leal. Quilombo Pedra do Sal. Belo Horizonte: FAFICH, 2016. Disponível em: http://www.incra.gov.br/sites/default/files/terras_de_quilombos_pedra_do_sal-rj.pdf Acesso em: 12/01/020.

COSTA, Alex Franulovic da. Porto Maravilha: a evolução urbana da região portuária e os cinco primeiros anos da operação urbana consorciada. Rio de Janeiro: EPPGG, 2015.

GOMES, Edlaine de Campos. Herdeiros da Pequena África: Narrativas Descompassadas. Ponto Urbe [Online], 2014. Disponível em http://pontourbe.revues.org/1423 Acesso em: 10/12/ 2019. 
HONORATO, Cláudio de Paula. Valongo: o mercado de escravos do Rio de Janeiro (1758 a 1831). Dissertação de Mestrado-UFF, 2008. Disponível em: http://www.historia.uff.br/stricto/teses/Dissert-2008 . Acesso em: 10/03/2020.

IPHAN. Proposta de inscrição do sítio arqueológico Cais do Valongo na lista do patrimônio mundial. 2016.2 Disponível em: http://portal.jphan.gov.br/uploads/ckfinder/arquivos/Dossie_Cais_do_Valongo_versao _Portugues.pdf. Acesso em: 10/02/2020.

KRISNAS, Antonio. Kabeça Urbana. Revista África e Africanidades - Ano 2 - n. 5 Maio. 2009. Disponível em: http://africaeafricanidades.net/documentos/Kabeca_Urbana_edicao5_.pdf Acesso em: 12/07/2020.

KOK, Glória. Rio de Janeiro na época da Av. Central. São Paulo: Bei Comunicação, 2005.

LIMA, Luciana Leite; D’ASCENZI, Luciano. Políticas públicas, gestão urbana e desenvolvimento local. Porto Alegre: Metamorfose, 2018. ISBN: 978-85-53074-068.Disponível em: https://www.editorametamorfose.com.br/ebooks/politicaspublicas.pdf . Acesso em: 25/07/2020.

LIBÓRIO, Daniela Campos, SAULE JÚNIOR, Nelson. Princípios e instrumentos de política urbana. Enciclopédia jurídica da PUC-SP. Celso Fernandes Campilongo, Alvaro de Azevedo Gonzaga e André Luiz Freire (coords.). Tomo: Direito Administrativo e Constitucional. Vidal Serrano Nunes Jr., Maurício Zockun, Carolina Zancaner Zockun, André Luiz Freire (coord. de tomo). 1. ed. São Paulo: Pontifícia Universidade Católica de São Paulo, 2017. Disponível em: https://enciclopediajuridica.pucsp.br/verbete/76/edicao-1/principios-e-instrumentosde-politica-urbana Acesso em: 25/07/2020.

NOEMI, Marujo. O Estudo Académico do Turismo Cultural. Revista Turismo y Desarrollo Local. vol 8 , ำ 18, 2015. Disponível em: $<$ https://dspace.uevora.pt/rdpc/bitstream/10174/16716/1/NOEMI\%202015\%20- 
\%200\%20ESTUDO\%20ACAD\%C3\%89MICO\%20DO\%20TURISMO\%20CULTURA L.pdf> Acesso em: 06/12/2019.

PEREIRA, Júlio César Medeiros da Silva. À flor da terra: o cemitério dos pretos novos no Rio de Janeiro. Rio de Janeiro: Garamond, 2007.

RIO DE JANEIRO, Prefeitura da Cidade do. Decreto 34.803, de 29 de novembro de 2011.

Disponível em http://portomaravilha.com.br/conteudo/legislacao/decretos/d34803.pdf Acesso em: 13/03/2020.

Lei Complementar $n^{\circ}$ 101, de 23 de novembro de 2009. Disponível em http://portomaravilha.com.br/conteudo/legislacao/leis-complementares/LC101_23112009.pdf Acesso em: 10/01/2020.

Lei 8105 de 20 de setembro de 2018. Disponível em https://govrj.jusbrasil.com.br/legislacao/629646654/lei-8105-18-rio-de-janeiro-rj Acesso em 10/01/2020.

SOARES, Carlos Eugênio Líbano. Valongo, cais dos escravos: memória da diáspora e modernização portuária na cidade do Rio de Janeiro, 1668 - 1911. Relatório de estágio de pós-doutoramento, Departamento de Antropologia, Museu Nacional (UFRJ), Rio de Janeiro, 2013.

TAVARES, Reinaldo Bernardes. Cemitério dos Pretos Novos, Rio de Janeiro, século XIX: uma tentativa de delimitação espacial. Universidade Federal do Rio de Janeiro, Museu Nacional, Departamento de Antropologia, Programa de PósGraduação em Arqueologia, Rio de Janeiro, 2012.

TONELLA, Celene. Políticas urbanas no Brasil: marcos legais, sujeitos e instituições. Brasília , v. 28, n. 1, p. 29-52, 2013. Disponível em: http://www.scielo.br/scielo.php?script=sci_arttext\&pid=S010269922013000100003\&Ing=en\&nrm=iso . Acesso em: 25/07/2020. 
UNESCO. Convenção para a salvaguarda do patrimônio cultural imaterial. Brasília: Iphan, 2003.2 Disponível em: $\quad$ http://portal.iphan.gov.br/uploads/ckfinder/arquivos/Convencao1972\%20\%20br.pdf Acesso em: 06/02/2020.

Enviado: Julho, 2020.

Aprovado: Agosto, 2020. 